\title{
Study on the Importance of Doctors' Attentive Duties
}

\author{
Na Wang \\ Department of Anesthesiology \\ The First Hospital of Jilin University \\ Changchun, China \\ wangna080613@163.com
}

\author{
Jinguo Wang* (corresponding author) \\ Department of Urology \\ The First Hospital of Jilin University \\ Changchun, China \\ wangjinguolily@163.com
}

\begin{abstract}
Reasonable doctor standard and medical standard are the standards for judging doctors attentive duties. The attentive duties of doctors include informing duties, reasonable treatment duties and faithfully maintaining secrecy. To understand doctors' attentive duties correctly is very important for the judgement in medical disputes, because doctors' duty of care is the core content of medical damage compensation liability. This paper is focused on its applicability which is wide and can make up the defects of the law.
\end{abstract}

Keywords-doctors; attentive duties; medical disputes; compensation

\section{INTRODUCTION}

The doctor's duty of care physician in the medical behavior should be attention and skills, it requires physicians to concentrate, careful treat may emerge in the medical practice of medical risk, do its utmost to take reasonable measures to avoid damage to the patient. Laws, administrative regulations, the rules and regulations of technical operation, the diagnosis and treatment of the statutory duty of care are all included. Under special circumstances, the law can use the principle of rationality, foreseeable principle and principle of trust owes a duty of care to determine whether the physician. For the balance of the interests of both doctors and doctors duty of care can change according to the development of medical technology, medical ideas constantly expanding its content. The doctor's duty of care medical treatment fault as the basis is also the key factors that determine the medical damage compensation responsibility

\section{THE DEFINITION OF DOCTORS’ ATTENTIVE DUTIES}

Determine the physician to perform the duty of care is a professional standard. First of all, professional standards for project implementation of the same diagnosis doctor medical behavior should reach the average technical level with secondary professional technical personnel. It contains the following contents: physicians should be timely medical new knowledge, reasonable and improve their medical skills into full play. In foresight, cautious, courage, judgment, self-control, selflessness, etc., the physician should reach the level of the medical profession generally. Physicians increase the degree of attention according to the severity of the medical risk. Second, accord with risk of medical practice treatments, the law and DE formula can be applied to protect the interests of patients, denied on behalf of the professional standards of medical practice. Finally still need to clear the following points: first, only when the objective factors such as medical equipment, medical environment have adverse consequences for diagnosis and treatment behavior [1].

Doctors duty of care has an important status in the doctorpatient relationship, only to fulfill the duty of care, patient demand of both sides can be satisfied, and to avoid medical dispute, the real purpose of medical treatment can be achieved, thus to build a harmonious doctor-patient relationship. The doctor's duty of care of medical negligence that the basis and the logical premise.

\section{THE IMPORTANCE OF DOCTORS`ATTENTIVE DUTIES}

\section{A. Medical malpractices}

Difficult to decide to become reality, the medical treatment fault drag is not found the root cause of medical disputes. The tort liability act is prescribed medical treatment fault is the legal premise of medical damage compensation responsibility of medical institutions. But not just medical treatment fault decide how to make specific provisions, there would be no from essentially solve the problem of medical treatment fault is difficult to maintain the legal reality. To solve in the practice of medical treatment fault recognition of the most effective way is to attach importance to the role of doctors duty of care, to determine the notice obligation principle and pay attention to the standard, the physicians note obligation is typed, hierarchical classification, a comprehensive regulation physicians, the specific content of the duty of care to establish medical damage compensation responsibility.

Through the analysis of related literature, it can be summed up the following features: first, the study of the notice obligation is in study the problem of medical negligence and medical damage compensation is involved, not too much detailed analysis. Therefore, the author can only from medical negligence and medical damage compensation super ordinate doctors duty of care in the literature of related content. Second, there is duty of care standard of medical negligence and doctors to determine the confusion of standard terms. 


\section{B. Medical negligence}

For recognition of medical negligence is the physician attention obligation to execute the status of identity, when the doctor not to do their duty of care is medical negligence, standard of medical negligence is the determination of the notice obligation standard, the intension and extension of the doctors' duty of care enough to cover the content of the medical negligence and medical behavior illegal. Third, when study the attention obligation, the division of a duty doctor. Some scholars pointed out that the obligation of physicians have a duty of care, duty of loyalty and obligation to keep confidential, and scholars pointed out that the doctor's duty of loyalty but the content of the duty of care. This article discusses the duty of care to determine doctors in law of professional skills and professional care, no need for doctors' duty division are discussed [2]. Moreover, the author thinks that, doctor's professional characteristic determines its commitment in various must be combined with their own skills and caution, physicians in the process of the duty of care through the fulfillment of other obligations, and for the other obligations.

\section{Concentration}

Man is engaged in an activity when there are certain things to maintain a cautious, serious psychological state. It requires the person to concentrate, careful carefully when the activity, so that you can know activity may be dangerous, to avoid danger. "Note" was able to rise to a legal obligation, because there is some relationship between related parties, need each other in their respective obligations, in a cautious, careful attitude towards issues related to the others, and enjoy each other's interests. Because in a certain relationship of the parties, may be due to the other party a certain activities and make their own interests suffered, but to avoid the loss, the law is necessary to put this note as an obligation, in order to avoid the damage could not happen." Because one of their own affairs or not carefully, not only may affect their interests, may also damage to other people's life and property safety, cautious at this time has become an obligation [3].

\section{HOW TO IMPROVE DOCTORS' ATTENTIVE DUTIES}

Duty of care is a kind of in order to avoid damage and statutory duty of proper attention. In law, the offender without liability for negligence will be punished, unless the damage of the ACTS or omissions shall be the duty of care to the plaintiff. If a person to reasonably foreseen that the adults. And on other artificial adults' for a possible injury or property damage, so, in most cases he owes a duty of care may be affected by its people. As a result, doctors have the obligation to pay attention to for its patients; highway motorists have the obligation to pay attention to deal with others. Sichuan 23 a duty of care consists of two aspects of attention and skill requirements, embodied in the experts on the duty of care, the former refers to experts in the process of practice with caution, pay attention to the attitude of the transaction, the prompt adoption of reasonable measures to avoid damage; the latter refers to the experts have a career in a particular competent people usually skills.

We believe that a duty of care is a relationship between the parties shall fulfill its obligation to cautious and responsible attitude, when the implementation of the behavior of the damaged the other interests in a possible dangerous situation, should do their utmost to foresee the risk, take appropriate measures to avoid danger. Duty of care includes both consciousness level, cautious, and contains the behavior when confronted with danger should be taken by the reasonable person.

The specific content of duty of care can be flexible according to the specific situation, but on the whole can be divided into: results foresee results and avoid obligations [5]. it results predicted obligation refers to the behavior person should foresee some injury consequence when behavior produces, it is on the premise of dangerous predictability. Predictability is the possibility to understands the objective risk, it depends on the objective risk occurrence probability, a damage could not have happened, so it's objective occurrence probability is zero, absolutely will occur when the objective is a chance. In judging the behavior of an objective risk occurrence probability, should with behavior this behavior belonging to the class of the risk occurrence probability for reference, and should not judge alone the risk occurrence probability of a specific behavior."

People on the concept of cognitive similarities are far greater than differences." Up results to avoid duty refers to the behavior person shall take appropriate measures when behavior, can't damage caused not allowed by law. Is not under any circumstances there is a duty of care, in the absence of a duty of care exists, if the offender can avoid the occurrence of harmful consequences did not avoid, causing injury consequence, behavior of person most is morally condemned rather than the legal responsibility. But in the case of existence of duty of care, for violating the results avoid causing damages to the obligations of the conductors must bear legal responsibility [4].

Results to avoid duty on the premise of can foresee danger and actor after foresee danger, must improve attention, take some reasonable measures to prevent the occurrence of harmful consequences or determined to leave the dangerous behavior will be carried out.

\section{DOCTORS' ATTENTIVE DUTIES CAN PREVENT MEDICAL MALPRACTICE}

It is a high-risk occupation health work, medical personnel legally unable to bear the liability for this risk, should strengthen the early to inform, let patients know should not only accept the medical service, to accept risk may be damaged. Patients agree to work is the medical tort liability is necessary conditions, is legitimacy medical work behavior under the premise of medical staff should be the purpose of each operation, risk factors, to inform the patient and family, for special treatment, nursing, inspect the consent of the patients, signing formalities when necessary, it is respect for the rights of patients is the need of medical workers to protect themselves.

\section{A. The lack of doctor-patient communication}

In daily life, there are a lot of medical disputes are caused by the lack of doctor-patient communication, therefore, we must strengthen the doctor-patient communication, to establish a good doctor-patient relationship, advocated the spirit of 
loving, must strengthen the implementation of the new medical model and the establishment of humanistic spirit, to persistent education of medical ethics and medical personnel, education they firmly establish a "taking patients as the center, the patient first" idea, and respect the rights of patients, and improve service, take the initiative to establish equal relationship with the patient. Strengthen the doctor-patient communication, is to reduce medical disputes, an important means to ease the doctor-patient relationship.

\section{B. Strengthen the legal knowledge popularization}

Strengthen the legal knowledge popularization medical staff, strengthening the legal system idea, in view of the existing or potential of prone to problems and hidden dangers of nursing disputes, from the Angle of law, some foundation for education. To strengthen the professional medical practitioners law ", "regulations on the medical accident treatment such as learning, enable staff to realize the new situation of the citizen's legal consciousness and enhance ego to protect consciousness gradually. We want to know how to avoid malpractice at the same time.

In the process of dispute resolution, the patient is in the center of the whole incident, patients of complaints handling requirements, often to a large extent influenced by hospital attitude. So whatever the real reason for complaint, as a medical staff, must pay attention to reception way, understand their standing in the patient's party. As in the early days of the dispute on high pressure treated, it often can create conflict, forcing patients to lodge a complaint. You should be more about how to alleviate, facilitating the ultra-emotions, make must be good at coordination and stable, to listen more and don't rush to defend himself. As there is objectively party in a weak position information, the information asymmetry phenomenon, therefore, the medical staff should establish the communication with patients, with respect, understanding, compassion mind and lead the conversation, to explain, in order to promote mutual understanding and trust, expand control events, important as olive-branch.

\section{Improve professional activity}

Visible, in a professional activity, as a result, foresee a compulsory requirement act before for a specific behavior, a cognitive response to the behavior of behavior, the cognition to the "law" has been class behavior, on the basis of forming the basic attention. Results avoid obligation is the obligation of prediction about the results, it requires that the offender in the concrete behavior, guided by the previous form the basic attention, play their own capacity, according to the specific situation of all possible danger to take effective measures to avoid. However, in the event of a "law" is not such behavior, a comprehensive behavior person of ability, second, we must comprehensive behavior person's environment, and then judge the behavior person whether can foresee danger, avoid dangerous conditions [6]. Able to foresee the foreseeable risk of Yang, actor and actor take measures to prevent danger to become established three factors of duty of care. Therefore, the purpose of law in protecting the interests of most people, the need to clear some actor's duty of care, in order to better protection of the interests of others affected by its behavior.
The author thinks that, from the result of foresee results and avoid obligations can be realized in the analysis, the duty of care is not an obligation, but rather a series of obligations, it for the other obligations, throughout the fulfillment of other obligations in the process, is the basis of a person to perform its obligations, could meet the legal requirements. Doctor to the patient's interrogation obligations, for example, is a legal obligation or obligations agreed upon, but how to interrogation, interrogation effect judgment is a duty of care. That is to say, the judgment of physician visits an obligation and the category of duty of care is physicians.

\section{Enhance duty of care}

Duty of care is one of the core concepts in contract law, is also one of the core concepts of tort law. It is so important, mainly because it can relate actor's illegal behavior and subjective fault and make some changes in the component elements of legal responsibility. Such as on the tort liability imputation, our country civil law theory, USES is "four elements", namely the subjective fault, illegal behavior and damage consequence, a causal relationship between illegal behavior and damage consequence, these four requirements are all capable to establish legal liability. But if the duty of care to judge the legal responsibility, you can follow this train of thought: the person responsible for the legal duty of care, the person did not fulfill the corresponding duty of care or their behavior does not meet the standard of care required duty of care, damage does not allow the legal consequences of the behavior person should bear corresponding responsibility [6].

Therefore, the duty of care can save legal responsibility judgment procedure, improve the efficiency of dispute resolution. And the role of duty of care in the doctor-patient relationship is mainly manifested in the following aspects: first of all, the duty of care provides legal objective standard for medical behavior, facilitate the public's understanding of health behavior law content, better in protecting the interests of both doctors. At present, the main cause of medical disputes appear is that both sides information asymmetry, the prescriptions think they fulfill their obligation to the various medical has conforms to the medical level, but with side because they do not understand the medical behavior, medical actions did not reach the expected treatment effect, bring to their damage. Law needs a fair evaluation of medical behavior, both cannot be identified at the rhetoric of the prescriptions of his legal behavior, is not only to the patient's subjective expectations to the medical damage compensation responsibility. The results of the medical behavior is uncertain, only to a duty of care of specific objective requirement to comprehensive examination doctor medical behavior, to find a interests balance in between doctor and patient.

\section{CONCLUSIONS}

Finally, doctors' duty of care is the core content of medical damage compensation liability, the applicability is wide and can solve the law there is no special infringement case, the law has flexibility and justness. These two kinds of obligations only in physician explained the connotation of the duty of care. Doctors' duty of care requires physicians to study relevant medical literature and new treatment method, do well to be a 
justice standard requires caution should fulfill the duty of the physician, as long as the physician completely fulfills the duty of care, even if the injury consequence, physicians will also be able to escape. Because the standard of medical treatment fault recognition is the definite standard of the doctors' duty of care, as long as the medical behavior does not meet the requirements of the notice obligation standard, caused certain damage consequence, a medical institution shall assume the corresponding medical damage compensation responsibility. Doctors duty of care standard is the embodiment of the duty of care in terms of the degree of attention, is also the medical tort liability law that the most important factors.

\section{REFERENCES}

[1] Felicity Hasson, Sinead Keeney, Hugh McKenna. Research guidelines for the Delphi survey technique[J]. Journal of Advanced Nursing. 2008 (4)

[2] Julian de Meyrick. The Delphi method and health research[J]. Health Education. 2003 (1)

[3] Titus Schleyer, Kenneth A. Eaton, David Mock, Victoire Barac'h. Comparison of dental licensure, specialization and continuing education in five countries[J]. European Journal of Dental Education. 2002 (4)

[4] Emilie Roberts, Nicholas Mays. Can primary care and community-based models of emergency care substitute for the hospital accident and emergency (A \& E) department?[J]. Health policy. 1998 (3)

[5] Sudeh Cheraghi-Sohi, Peter Bower. Can the feedback of patient assessments, brief training, or their combination, improve the interpersonal skills of primary care physicians? A systematic review. BMC Health Services Research . 2008

[6] Taylor RB. Family medicine: current issue and future practice. Family Medicine-Practice. 1998. 